\title{
Medication practices and experiences of older adults discharged home from hospital: a feasibility study protocol
}

This article was published in the following Dove Press journal:

Patient Preference and Adherence

\author{
Pauline Roux' \\ Filipa Pereira ${ }^{2}$ \\ Marie Santiago-Delefosse \\ Henk Verloo ${ }^{2}$ \\ 'University of Lausanne, Institute \\ of Psychology, Research Center for \\ Psychology of Health, Aging and Sport \\ Examination, Lausanne, Switzerland; \\ 'University of Applied Sciences \\ and Arts Western Switzerland, \\ Department of Nursing Sciences, \\ Sion, Switzerland
}

Background: Switzerland's aging population raises pressing questions about maintaining older adults in their home environments and the problems associated with managing complex treatments requiring medication in such contexts. Few studies have examined older adults' experiences of changes in their medication on discharge home following hospitalization for illness or an accident. Similarly, few studies have evaluated the involvement of informal and professional caregivers in the medication practices used with older adults living at home. However, medication practices are complex and understanding them requires an interest in their underlying logic and the interactions that constitute them. This study will explore the feasibility of recruiting older adults and then collecting and analyzing data on their medication practices and their experiences of discharge home after hospitalization for an illness or following an accident. Furthermore, it will describe the involvement of informal caregivers and homecare professionals in these processes.

Design and methods: The study will use a qualitative methodology. The first phase will be developed in the general medicine and surgery wards of Sion hospital and in the town's community healthcare center. This phase will aim to build a close collaboration between the research team and the health care professionals of Valais hospitals and the community healthcare center. It will enable data collection from professional caregivers to identify the tools, and potentially the interventions, which are used to prepare older adults for hospital discharge and return home, particularly with regard to the medication prescribed to them. In the second phase, semi-structured interviews will be conducted with eight patients aged 75 years old or more who have returned home after hospitalization. Interviews will also be conducted with their informal and professional caregivers.

Conclusion: This feasibility study will enable the identification of tools that leverage improved adhesion to a medical treatment that has been adjusted and stabilized following discharge home from hospital. It will incorporate the points of view of older adults and the different stakeholders involved in the management of their medication and the development of tangible solutions to encourage treatment adhesion on discharge home. This study's findings will enable us to design a much larger future study.

Keywords: medication practices, experiences, older adults, discharge home, informal caregivers, homecare professionals, primary care, home dwelling older adults, home care, nurses, family physician

\section{Background}

The demographic transition being brought about by Switzerland's aging population raises questions about the place of older adults within our society. ${ }^{1-3}$ The majority of people age relatively well, even with one or more stable chronic diseases. ${ }^{4,5}$ However, 
a significant proportion of very old adults have crippling chronic diseases or unstable multimorbidity requiring multiple treatment components involving complex medication. ${ }^{6}$ This leads to more and more questions about the relevance and safety of medication treatments for this population. ${ }^{6}$ Issues relating to medication for older adults must increasingly be addressed in the context of patients living in their own homes. Indeed, in 2013, Switzerland could only accommodate $16.8 \%$ of its population aged 80 years or more in nursing homes. ${ }^{7}$

Both political and public health actors agree on the need to maintain older adults in their homes for as long as possible. ${ }^{8}$ This agreement will make it possible to cope with the limited capacity available in nursing homes and the considerably higher costs of hospital and nursing-home care compared with the provision of homecare. ${ }^{7,9}$ Moreover, this political will is consistent with the wishes expressed by the majority of older adults themselves. Indeed, several authors have documented that 9 out of 10 older adults wish to stay at home as long as possible. ${ }^{7,10}$

Maintaining old and very old adults in their homes when they have already lost a certain amount of autonomy has major consequences on the organization of care: they can manage certain dimensions of their own care or treatments, but there is also a need for the involvement of professional caregivers, home helps, and informal caregivers. ${ }^{11}$ Medication management is an integral part of the daily life of older adults and a necessary condition for maintaining them at home. Moreover, taking into account the high prevalence of multimorbidity in this population, medication management often becomes a determinant of an older adult's state of health and quality of life at home. ${ }^{12}$

Several studies have reported that older adults are at high risk of poor adherence to treatment, including missed doses, discontinuation of treatment, changes in schedules and/or doses, or excessive use. ${ }^{13,14}$ Misuse of certain categories of drugs, such as sleeping pills, analgesics, tranquilizers, as well as appetite suppressants and stimulants, is common. ${ }^{15}$

Problems associated with low or no therapeutic adherence are all the more evident in the sensitive period of discharge home from hospital. ${ }^{16}$ Nonadherence may lead to a degradation in the patient's clinical condition, shortterm, avoidable hospitalization or readmission, physical and cognitive decline, an exacerbation of chronic medical conditions, and increased health costs. ${ }^{16-18}$ Several authors have documented that about $30 \%$ of the avoidable readmissions of older adults are directly related to nonadherence to the physician's prescription. ${ }^{19,20}$ Other studies have reported on the indirect impacts of the adverse effects of drug nonadherence, such as falls, dehydration, or acute confusion, that may lead to hospitalizations and readmissions. ${ }^{21}$ Older adults often undergo changes in their posology and prescribed medication during hospitalization ${ }^{22}$ and in the first few months after hospital discharge due to comorbidities and the need for disease stabilization. ${ }^{17}$ Such changes tend to decreased adherence. ${ }^{23}$ Older adults may also continue to take medications that were discontinued during hospitalization, fail to begin a new treatment initiated during hospitalization, or take incorrect dosages. ${ }^{16}$ Indeed, they are particularly at risk of nonadherence in the first days or weeks after hospital discharge.${ }^{16}$ In addition, older adults taking five or more drugs are considered to be more susceptible to the consequences of polypharmacy, such as adverse drug reactions, drug-drug interactions, nonadherence, or drug-food interactions. ${ }^{24}$

A limited number of studies have focused on the personal perspectives of older adults' experiences of returning to their homes after hospitalization. ${ }^{25,26}$ These few works indicated that older adults felt that there was a lack of clear, understandable explanations about changes to medication at hospital discharge, and that there was little opportunity to question health care professionals about their medication during their hospital stays. ${ }^{27,28}$ Inadequate explanations about medications not only result in omissions and incorrect dosages, but also anxiety and confusion in older adults. ${ }^{29}$ Although patients have different information needs about their drugs in this transitional phase, most would like to receive basic information about their treatments. ${ }^{30,31}$ Weak communication between hospital physicians and general practitioners (GPs) or pharmacists has also been described. ${ }^{32-35}$ However, the GP appears to be the key person influencing the proper use of new prescriptions initiated in the hospital. ${ }^{28}$ Despite the significance of these studies, they did not extend to the medication practices of older adults returning home after hospitalization, or their adherence and adjustments over time. They also failed to identify the involvement of professional or informal caregivers in this sensitive context. Moreover, this specific issue has not, to the best of our knowledge, been studied in the Swiss context. Although a large number of studies have focused on adherence to medication treatments for specific pathologies, such as chronic cardiovascular disease or diabetes, ${ }^{36,37}$ the context of return home after hospital discharge has not been addressed, and the main methods used in these studies did not allow for reporting on older adults' medication practices or their personal experiences. Some studies have identified the operational strategies which older adults living at home use to integrate new drugs into their daily habits and change some of their routines, ${ }^{38}$ especially for 
remembering to take medication. ${ }^{39}$ The strategies are choreographed into broader daily routines, ${ }^{40}$ and older adults' recall methods rely on spatial characteristics within their homes and on the temporal rhythms of their day. ${ }^{41}$ However, further studies are essential to identify the logic which older adults use to manage daily changes in their medication and dosing regimens following hospitalization, while integrating these into the rhythm of their daily lives and the spaces in their homes. Several studies have examined the involvement of homecare professionals and informal caregivers, but significant questions remain unanswered. On leaving hospital, medication is often managed by the older adult and his/her family, in partnership with the attending GP, a community health care nurse, or a pharmacist. ${ }^{42}$ Experimental studies, such as randomized controlled clinical trials, have examined the effectiveness of interventions by nurses alone or in collaboration with other stakeholders on home-based older adults' drug adherence. Although the role of community health care nurses is fundamental, partly because of their proximity to patients and partly because of their role as an interface between patients, pharmacists, and physicians, ${ }^{43}$ these studies often revealed how relatively ineffective interventions were and how poor drug adherence was, without any analysis of their etiology. ${ }^{44}$ Several other studies have investigated the impact of the quality of health care relationships on the medication practices of home-dwelling older adults, ${ }^{38,45}$ particularly in the process of therapeutic adherence. ${ }^{46,47}$ However, they did not consider the specific context of return home after hospitalization. This review of the literature showed that there is a need for studies in Switzerland to help understand the medication practices of home-dwelling older adults discharged from hospital. These studies should involve patients' perceptions, as well as those of their informal caregivers and home health care professionals.

\section{Theoretical framework of the study}

Based on an interdisciplinary study combining health psychology and nursing sciences, this project will explore the feasibility of collecting and analyzing data on the medication practices and experiences of older adults returning home after hospitalization for illness or following an accident. It is a feasibility study to test the relevance of the methodology for a planned larger future study. It integrates an examination of how professional and informal caregivers are involved in these practices and experiences. To accomplish this objective, the patient care circle for care transitions of Lee et $\mathrm{al}^{48}$ and the framework of medication adherence among older adults of Murray et $\mathrm{al}^{49}$ will guide the research project.
The chosen approach considers the different dimensions of medication practices and their underlying logic. ${ }^{15,50}$

- The personal dimension: medication practices take place in the private spatiotemporal existence of everyday life, where older adults' habits, routines, and personal preferences are juxtaposed and removed from the formal world of health care institutions. ${ }^{51}$

- The community and social dimension: on the one hand, medication practices involve all the other actors involved in the everyday life of older adults, and are thus the result of a co-construction; on the other hand, they are steeped in shared values, norms, and social representations. ${ }^{50}$

The questions presented below will guide this feasibility study before a future large-scale study is conducted:

- How do older adults who have returned home manage their medication after hospitalization for an illness or following an accident?

- What are the medication practices and experiences of older adults who have been discharged home? What are older adults' perceptions of the place that their medication takes within their private space and everyday life? Which of the medication practices used by older adults facilitate or hinder drug adherence in this context of change?

- Who is involved in the management of older adults' medication when they return home? At what level, frequency, or intensity are they involved? What place does medication take in the relationship between the older adult and those around him/her (informal or professional caregivers)? What place does medication take in affirming or refuting the older adult's status as a sick person, or in justifying a need for support from health care professionals and informal caregivers?

\section{Design and methods Design}

This feasibility study will take place in two phases. The first phase will take place in Sion's acute care hospital and in the town's community healthcare center (CHC). It will identify the current means, interventions, and practices used to prepare older adults for hospital discharge, particularly with regard to their prescribed medications. It will also build a close collaboration between the research team and Valais hospitals' and CHC's health care professionals. It will involve them in data collection, and thus strengthen the project's relevance and its relevance to the needs of health care professionals.

The second phase will focus on collecting data from older adults discharged from hospital and their informal and professional caregivers. In addition to being based on 
the perceptions of the actors involved, the originality of this study is to integrate three types of regards to help understand older adults' experiences of medication practices.

The proposed study will rely on different specific data collection methods which favor a focus on the actual practices used by older adults to manage their medication. We will use individual interviews, joint interviews, medication journals, and walking interviews using household photographs.

Generating data through multiple methods and different points of view will enable the researchers to triangulate data and sources. Every method and data source provides another perspective on the phenomenon studied; each method helps to give us a better overall vision. ${ }^{52}$ Finally, the older adults will be interviewed at several points in time. This methodological design will make it possible to analyze any evolution in their medication practices and experiences following their discharge from hospital.

\section{Study setting}

This study will be conducted in the canton of Valais in Switzerland. It will rely on a close collaboration between the research team and Valais hospitals and CHC.

\section{Participants' characteristics}

The study's first phase will involve nurse supervisors from the Surgery and General Medicine wards at Valais hospitals and from the $\mathrm{CHC}$, who will be interviewed, as will liaison nurses. The Surgery and General Medicine wards were selected based on their high numbers of hospitalized older adults with high rates of comorbidity and polypharmacy. ${ }^{53}$
Liaison nurses ensure seamless health care between hospitals and the community. We consider their participation to be essential to the study.

The study's second phase will involve three groups of participants: older adults discharged home from hospital after illness or accident $(n=12)$, their informal caregivers $(n=12)$, and their professional caregivers $(n=12)$. Older adults will be 75 years old or above, taking ongoing polymedication and supervised by a $\mathrm{CHC}$ which uses the comprehensive geriatric assessment tool - Resident Assessment Instrument for Home Care (RAI-HC).

We defined informal caregivers as any family member, neighbor, or a friend assisting a dependent older adult with certain activities of their daily life. This assistance, help, care, or physical presence must be given on a regular basis for at least two basic activities or instrumental activities of daily life or to ensure patient safety, for 6 months or more. ${ }^{54}$ The informal caregiver will be included in the study if the recruited older adult identifies that person as being significant in the management of their medication and if they give written informed consent to participate.

Professional caregivers are those employed to provide professional home health care services (ie, nurses, nursing assistants). He/she will be included in the study if the recruited older adult identifies him/her as the professional most involved in his/her medication management.

Older adults and informal caregivers will be assessed on their capacity for judgment and their ability to speak and understand French. Table 1 presents the specific inclusion/ exclusion criteria for each group of participants.

Table I Inclusion and exclusion criteria

\begin{tabular}{|c|c|c|}
\hline Participants & Inclusion criteria & Exclusion criteria \\
\hline Older adults & $\begin{array}{l}\text { - Aged } 75 \text { years or above } \\
\text { - Man or woman } \\
\text { - Hospitalized in general medicine or surgery ward at Valais hospitals } \\
\text { - Capacity for judgment as assessed and confirmed by a physician } \\
\text { - Able to speak and understand French } \\
\text { - Living alone or in a couple, in a rural or urban area in the region } \\
\text { - Monitored by a CHC in the canton of Valais (before hospitalization) which uses the } \\
\text { - RAl-HC geriatric assessment tool } \\
\text { - Daking at least five different medications }\end{array}$ & $\begin{array}{l}\text { A stay in a nursing home or } \\
\text { rehabilitation center has been } \\
\text { planned }\end{array}$ \\
\hline $\begin{array}{l}\text { Informal } \\
\text { caregiver }\end{array}$ & $\begin{array}{l}\text { - Designated by the older adult as the most significant informal caregiver involved in } \\
\text { medication management } \\
\text { - Capacity for judgment } \\
\text { - Able to speak and understand French } \\
\text { - Aged } 18 \text { years or above }\end{array}$ & \\
\hline $\begin{array}{l}\text { Professional } \\
\text { caregiver }\end{array}$ & $\begin{array}{l}\text { - Employed in professional homecare services for at least } 6 \text { months } \\
\text { - Registered nurse, nursing assistant, or GP } \\
\text { - Designated by the older adult as having a key role in medication management }\end{array}$ & $\begin{array}{l}\text { - Interim nurse for }<3 \text { months } \\
\text { - Student nurse } \\
\text { - Apprentice }\end{array}$ \\
\hline
\end{tabular}

Abbreviations: CHC, community healthcare center; GP, general practitioner; RAI-HC, Resident Assessment Instrument for Home Care. 


\section{Participant recruitment}

Four eligible older adults will be recruited from both the General Medicine ward and the Surgery ward using a non-probability sampling method with reasoned choice. Recruitment will be done in collaboration with nurses from these wards. They will briefly explain the study to the patient orally. The older adult will be asked for permission to release his/her name to the researchers. During the initial contact with the nurse, potential participants will be assured that accepting to give their names to the researchers will not oblige them to participate in the study. Those who agree to participate in the study will meet the researcher before their hospital discharge. The researcher will explain the study in detail, the written informed consent, and answer any relevant questions. In order to give the patient time to think, the same researcher will contact the older adult by telephone during the week following hospital discharge and ask for his/her agreement to participate in the study. In case of agreement, a first interview at home will be organized in the next few days.

\section{Description of data collection}

Data collection and analysis will be carried out by the authors, all experimented in qualitative research in the field of aging and/or health sciences.

\section{Data collection from Valais hospitals' and CHC's nurses}

An interview will be conducted with each nurse supervisor in the selected wards of Valais hospitals, and with liaison nurses in order to identify the means, interventions, and nursing practices used to prepare older adults for hospital discharge, with particular regard to the management of their medications. At Sion CHC, an interview will be organized with the nurse supervisor to explore the nursing interventions to do with medication.

In the second phase of data collection from older adults, their informal and professional caregivers will also be involved.

\section{Data collection from older adult}

During the first home meeting with the older adult, the researcher will provide all the details of the study. $\mathrm{He} / \mathrm{she}$ will be invited to sign the written informed consent form, allowing the researcher to collect sociodemographic and health data (RAI-HC) and to notify his/her GP. Participants will be given the option not to inform their GP. The researcher will suggest that the older adult participates in two semistructured interviews, with each lasting about an hour and the interviews spaced 3-4 weeks apart.
Data collection will begin at this first meeting, with a first semi-structured interview following an interview guide. In order to understand their experiences, the aim will be to collect the older adults' perspectives on hospitalization, the return home, information received about the treatment and its possible modifications, and the informal and professional caregivers involved. The older adult will be interviewed alone.

The researcher will then ask the participant to complete a week-long medication journal, ${ }^{29,55}$ either alone or with help from informal or professional caregivers. The researcher will explain this tool in detail, emphasizing that any information on daily medication routines is helpful, even if the older adult feels unable to complete the journal for the full 7 days. The instruction will mention the importance to note all the medicines taken, not only those prescribed by the doctors but also the other possible medicines. This will provide information on the daily routines associated with the participant's medication and will form the basis for the second interview.

The second interview will take place 3-4 weeks after the first one. It will be based on the participant's medication journal and will take the form of a walking interview ${ }^{56}$ using household photographs. Walking interviews lie between a standard interview and observation, recording the participant's discourse about his/her practices in association with an observation of the physical spaces and objects, such as the drugs mentioned by the individual, with which the older adult interacts moving through his/her everyday environment. The researcher will ask the participant to explain his/ her medication practices while pointing out the locations within his/her home where drugs are stored, prepared, and taken. The hypothesis underlying this methodology is that the physical presence of drugs promotes discussion..$^{57,58}$ We will identify and photograph, ${ }^{55}$ with the participants' agreement, the places where medication is stored, where the contact details for medical professionals and information are stored, and the locations of any other objects involved in daily care practices. The collection and analysis of photographs provides a better understanding of the complexity of medication management in home settings. They help to capture the interviewee's concerns or strategies when they are pointed out to the interviewer. The interview guide will investigate the self-medication issue to see the extent and influence of this practice.

\section{Data collection from informal caregivers}

A joint interview ${ }^{59}$ with the older adult and his/her principal informal caregiver ${ }^{29}$ will be organized at the patient's home 1-2 weeks after the second interview with the older adult. 
This type of interview provides access to the interactions between older adults and their informal caregivers with regards to medication management. We hypothesize that the main informal caregiver is deeply involved in the older adult's experience of medication management, but the caregiver's ideas about this may be similar to, overlapping with, or different from those of the older adult.

\section{Data collection from professional caregivers}

A semi-structured interview of about 1 hour will be conducted to explore the older adult's medication practices and other issues associated with the return home after hospitalization from the point of view of his/her professional caregiver. This will take place at the $\mathrm{CHC}, 1-2$ weeks after the joint interview which brought together the older adult and his/her informal caregiver.

\section{Feasibility indicators}

Several indicators will be collected in order to obtain accurate data with which to carefully plan the subsequent largescale study. A diary will be used to collect data during both the phases of the study, including collaboration with field partners, ease of and time necessary for recruitment, number of refusals to participate, and the facilitators, barriers, and time needed for the different components of data collection from the participants, informal caregivers, and health professionals.

Access to the field will be facilitated by a partnership between researchers from the University of Applied Sciences and Arts Western Switzerland, based in canton of Valais, and Valais hospitals and $\mathrm{CHC}$.

One of the risks already identified concerns the intrusive nature of exploring patients' homes and finding out about their medication use. Participants may feel exposed or vulnerable when dealing with someone whom they may associate with medical authority. They may feel threatened or judged by the researcher if they believe that their adherence to treatment and their ability to live at home independently is being assessed. ${ }^{60}$ The research team will remain very attentive to patients' perceptions and will strive to be caring in this context. The oral and written information provided to the participants will particularly emphasize that the researchers are independent and non-judgmental about medication practices. Participants will receive all possible details about the study's ethical provisions (information leaflets, informed consent forms, oral and written information about how data will be exploited throughout the research protocol, the freedom to withdraw from the study at any moment, the independence of researchers from professional caregivers).

\section{Data analyses}

A database will be prepared in an Excel $2013^{\circledR}$ format to record the participants' sociodemographic data. Data on the participants' health statuses will be collected using the RAI-HC data at the $\mathrm{CHC}$ and will be analyzed using the IBM-SPSS $^{\circledR}$ version 25.0. This will enable a description of participants' sociodemographic characteristics, such as age, sex, marital status, education, type and place of residence, level of education, and previous employments. Besides health status, the RAI-HC will provide a profile of each participant, his/her hospitalizations, and the health care providers involved.

The data collected via the interviews will be examined according to an analysis plan that integrates and compares two different analytical methods: 1) thematic content analysis ${ }^{6,61}$ using NVivo v. $11^{\circledR}$ software; using this method, the themes identified emerge from the data and provide a rich and detailed account of the data set; themes can be compared by different members of the analysis team until consensus is reached and 2) lexicometric analysis, using Iramuteq software, is a technique derived from the Alceste ${ }^{\circledR}$ method; ${ }^{62}$ the program allows a very fine exploration, both within each interview and across the whole corpus of interviews, of the structures that underlie the discourse.

Each older adult's medication journal will be analyzed and categorized according to the same principles as the interviews. The data collected in these documents will be put into perspective by the analysis of the interviews.

In the final data analysis, links will be made between the interviews, the medication journal, the patient's medical data records and prescriptions, and the photos of the drug locations.

Feasibility indicators will be analyzed using descriptive statistics.

\section{Ethics approval and consent to participate}

The research protocol has been approved by the Human Research Ethics Committee of the Canton Vaud (201701025). Written informed consent will be obtained from all participants before data collection commences, and confidentiality will be ensured and preserved in all cases.

\section{Discussion}

This study's added value lies in its combination of professional, academic, and applied research skills to investigate a public health problem. Indeed, the study will have an impact on older adults, their informal caregivers, and health care professionals. It will contribute to a better understanding of the as-yet poorly evaluated component reasons of why 
vulnerable older adults living at home do or do not adhere to their medication. It will enable an exploration of the tools that leverage improved adherence to a medical treatment that has been adjusted and stabilized following a discharge home from hospital. The findings will also help to avoid future negative consequences such as falls, acute confusion, or rehospitalization. The integration of the perspectives and points of view of older adults themselves, in conjunction with those of the other actors involved in their medication management at home, should aid the development of tangible, inter-professional solutions to encourage medication adhesion after hospital discharge home. The knowledge produced will be shared with the health care professionals at Valais hospitals and $\mathrm{CHC}$ during feedback sessions.

Scientifically, this study is interesting because of its collaborative, inter-professional approach combining health psychology and nursing sciences, an original methodology and the use of existing data (RAI-HC data) to build or reinforce collaborative networks.

The World Health Organization recommends interprofessional collaboration as a means of ensuring optimal quality of care in complex cases and situations. ${ }^{63} \mathrm{Commu-}$ nications and publications in relevant scientific journals will highlight and promote the methodologies used and the new knowledge revealed. The study's findings will be used to design a future larger-scale study.

\section{Role of the sponsors}

The sponsors will play no role in the design or conduct of this study, data collection, management, analysis, or data interpretation; nor in the preparation, review, or approval of the manuscript.

\section{Acknowledgments}

This study will be funded partly by the University of Lausanne and partly by the Department of Nursing Sciences, University of Applied Sciences and Arts Western Switzerland, Sion, Switzerland.

\section{Author contributions}

All of the authors contributed to the development of this study concept, the study design, and the drafting of the manuscript. They all approved the final version and agreed to be held accountable for all aspects of the work.

\section{Disclosure}

The authors declare that they have no conflicts or competing interests in this work.

\section{References}

1. Monod S. Promoting good clinical care to prevent elder abuse: comment on "Elderabuse as a risk factor for hospitalization in older persons". JAMA Intern Med. 2013;173(10):917-918.

2. Schoon Y, van Iersel MB, Jacobsen DE, Smit JW, de Boer MJ, Olde Rikkert MG. Betere ziekenhuiszorg voor zieke ouderen: sturing op kwetsbaarheid en patiëntendoelen [Improved hospital care for elderly patients: guidance on vulnerability and goal assessment]. Ned Tijdschr Geneeskd. 2013; 157(34):A6224. Dutch.

3. Rogers AC. Vulnerability, health and health care. J Adv Nurs. 1997;26(1): 65-72.

4. Monod-Zorzi S, Seematter-Bagnoud L, Büla C, Pellegrini S, JaccardRuedin H. Swiss Health Observatory; 2007. Maladies Chroniques Et Dépendance Fonctionnelle Des Personnes Agées: Données Epidémiologiques Et Economiques De La Littérature [Chronic disease and functional dependence of the elderly: epidemiologic and economic literature]. Available from: https://www.obsan.admin.ch/sites/default/ files/publications/2015/ad25.pdf. Accessed January 15, 2018. French.

5. World Health Organization (WHO); 2015. World report on ageing and health 2015. Available from: http://www.who.int/ageing/events/ world-report-2015-launch/en/. Accessed January 15, 2018.

6. Bachmann N, Burla L, Kohler D. Swiss Health Observatory; 2015. La santé En Suisse - Le point sur les maladies chroniques: Rapport national sur la santé 2015 [Health in Switzerland - update on chronic disease: health 2015 national report]. Available from: https://www. obsan.admin.ch/fr/publications/la-sante-en-suisse-le-point-sur-lesmaladies-chroniques. Accessed January 15, 2018. French.

7. Füglister-Dousse S, Dutoit L, Pellegrini S. Swiss Health Observatory; 2015. Soins de longue durée aux personnes âgées en Suisse. Evolutions 2006-2013 [Long term care in the elderly in Switzerland. Developments 2006-2013]. Available from: https:/www.obsan.admin.ch/fr/ publications/soins-de-longue-duree-aux-personnes-agees-en-suisseevolutions-2006-2013. Accessed January 15, 2018. French.

8. Paccaud F, Peytremann-Bridevaux I, Heiniger M, Seematter-Bagnoud L. Vieillissement: Eléments Pour une Politique De Santé Publique [Aging: evidence for a public health policy]. Lausanne: CHUV; 2010. French.

9. Höpflinger F, Hugentobler V. Swiss Health Observatory; 2011. Les besoins en soins des personnes agées en Suisse. Prévisions et scénarios pour le 21e siècle [The care needs of the elderly in Switzerland. Forecasts and scenarios for the 21 st century]. Available from: https://www.obsan. admin.ch/fr/publications/les-besoins-en-soins-des-personnes-agees-ensuisse. Accessed January 15, 2018. French.

10. Ennuyer B. Repenser Le Maintien à Domicile: Enjeux, Acteurs, Organisation [Rethinking home: issues, players, organization]. Paris: Dunod; 2006. French.

11. Williams GC, Patrick H, Niemiec CP, et al. Reducing the health risks of diabetes: how self-determination theory may help improve medication adherence and quality of life. The Diabetes Educator. 2009;35(3): 484-492.

12. Williams GC, Patrick H, Niemiec CP, et al. Reducing the health risks of diabetes how self-determination theory may help improve medication adherence and quality of life. Diabetes Educ. 2009;35(3):484-492.

13. Osterberg L, Blaschke T. Adherence to medication. NEngl J Med. 2005; 353(5):487-497.

14. Richardson K, Bennett K, Kenny RA. Polypharmacy including falls riskincreasing medications and subsequent falls in community-dwelling middle-aged and older adults. Age Ageing. 2015;44(1):90-96.

15. Menecier P, Fernandez L. Pratiques addictives dans la vieillesse [Addictive behavior among the elderly]. La Presse Médicale. 2012;41(12): 1226-1232. French.

16. Fallis BA, Dhalla IA, Klemensberg J, Bell CM. Primary medication non-adherence after discharge from a general internal medicine service. PLoS One. 2013;8(5):e61735.

17. Mansur N, Weiss A, Hoffman A, Gruenewald T, Beloosesky Y. Continuity and adherence to long-term drug treatment by geriatric patients after hospital discharge: a prospective cohort study. Drugs Aging. 2008;25(10):861-870. 
18. Nickel CH, Ruedinger JM, Messmer AS, et al. Drug-related emergency department visits by elderly patients presenting with non-specific complaints. Scand J Trauma Resusc Emerg Med. 2013;21(1):15.

19. Halfon P, Eggli Y, Pretre-Rohrbach I, Meylan D, Marazzi A, Burnand B. Validation of the potentially avoidable hospital readmission rate as a routine indicator of the quality of hospital care. Med Care. 2006; 44(11):972-981.

20. Tang VL, Halm EA, Fine MJ, Johnson CS, Anzueto A, Mortensen EM. Predictors of rehospitalization after admission for pneumonia in the veterans affairs healthcare system. J Hosp Med. 2014;9(6):379-383.

21. Bianco A, Molè A, Nobile CG, Di Giuseppe G, Pileggi C, Angelillo IF. Hospital readmission prevalence and analysis of those potentially avoidable in Southern Italy. PLoS One. 2012;7(11):e48263.

22. Shelton PS, Mozingo DB, Avissar PS, Karg M, Charboneau AL, Rich W. Measuring adherence in a community-based elderly population. Consult Pharm. 2012;27(11):771-781.

23. Poon DC, Ho YS, Chiu K, Chang RC. Cytokines: how important are they in mediating sickness? Neurosci Biobehav Rev. 2013;37(1):1-10.

24. Monégat M, Sermet C. Institut de recherche et documentation en économie de la santé; 2014. La Polymédication: définitions, mesures et enjeux: Revue de la littérature et Tests De Mesure [Polypharmacy: definitions, measures and issues: review of the literature and measurement tests]. Available from: http://www.irdes.fr/recherche/questions-d-economiede-la-sante/204-la-polymedication-definitions-mesures-et-enjeux.pdf. Accessed January 15, 2018. French.

25. Coffey A, McCarthy GM. Older people's perception of their readiness for discharge and postdischarge use of community support and services. Int J Older People Nurs. 2013;8(2):104-115.

26. Fredericks S, DaSilva M. An examination of the postdischarge recovery experience of patients who have had heart surgery. J Nurs Healthc Chron Illn. 2010;2(4):281-291.

27. Bagge M, Norris P, Heydon S, Tordoff J. Older people's experiences of medicine changes on leaving hospital. Res Social Adm Pharm. 2014; 10(5):791-800.

28. Stauffer Y, Spichiger E, Mischke C. Komplexe Medikamentenregime bei multimorbiden älteren Menschen nach Spital aufenthalt-eine qualitative Studie. Pflege. 2015;28(1):7-18. German.

29. Knight DA, Thompson D, Mathie E, Dickinson A. 'Seamless care? Just a list would have helped!' older people and their carer's experiences of support with medication on discharge home from hospital. Health Expect. 2013;16(3):277-291.

30. Borgsteede SD, Karapinar-Carkit F, Hoffmann E, Zoer J, van den Bemt PM. Information needs about medication according to patients discharged from the hospital. Patient Educ Couns. 2011; 83(1):22-28.

31. Kerzman H, Baron-Epel O, Toren O. What do discharged patients know about their medication? Patient Educ Couns. 2005;56(3): 276-282.

32. Hiance-Delahaye A, Teillet L, Lechowsky L, Aquino JP, Harboun M. Iatrogénie médicamenteuse, sujet âgé et lien ville-hôpital: enquête sur la transmission médicale hospitalière à la médecine générale [Druginduced pathogenesis, elderly subjects and the city-hospital link: survey of hospital medical transmission in general practice]. NPG Neurologie Psychiatrie Gériatrie. 2015;15(85):3-11. French

33. Pantilat SZ, Lindenauer PK, Katz PP, Wachter RM. Primary care physician attitudes regarding communication with hospitalists. Am J Med. 2001;111(9B):15S-20S

34. Mc Larnon E, Walsh JB, Ni Shuilleabhain A. Assessment of hospital inpatient discharge summaries, written for general practitioners, from a department of medicine for the elderly service in a large teaching hospital. Ir J Med Sci. 2016;185(1):127-131.

35. Rydeman I, Tornkvist L, Agreus L, Dahlberg K. Being in-between and lost in the discharge process - an excursus of two empirical studies of older persons', their relatives', and care professionals' experience. Int $J$ Qual Stud Health Well-being. 2012;7(0):1-9.

36. Annema C, Luttik ML, Jaarsma T. Reasons for readmission in heart failure: perspectives of patients, caregivers, cardiologists, and heart failure nurses. Heart Lung. 2009;38(5):427-434.
37. Neto PR, Marusic S, de Lyra Junior DP, et al. Effect of a 36-month pharmaceutical care program on the coronary heart disease risk in elderly diabetic and hypertensive patients. J Pharm Pharm Sci. 2011;14(2): 249-263.

38. Henriques MA, Costa MA, Cabrita J. Adherence and medication management by the elderly. J Clin Nurs. 2012;21(21-22):3096-3105.

39. Tordoff J, Simonsen K, Thomson WM, Norris PT. "It's just routine." A qualitative study of medicine-taking amongst older people in New Zealand. Pharm World Sci. 2010;32(2):154-161.

40. Sanders MJ, Van Oss T. Using daily routines to promote medication adherence in older adults. Am J Occup Ther. 2013;67(1):91-99.

41. Mickelson RS, Willis M, Holden RJ. Medication-related cognitive artifacts used by older adults with heart failure. Health Policy Technol. 2015;4(4):387-398.

42. Lauziere TA, Chevarie N, Poirier M, Utzschneider A, Belanger M. Effects of an interdisciplinary education program on hypertension: a pilot study. Can J Cardiovasc Nurs. 2013;23(2):12-19.

43. Van Camp YP, Van Rompaey B, Elseviers MM. Nurse-led interventions to enhance adherence to chronic medication: systematic review and meta-analysis of randomised controlled trials. Eur J Clin Pharmacol. 2013;69(4):761-770.

44. George J, Elliott RA, Stewart DC. A systematic review of interventions to improve medication taking in elderly patients prescribed multiple medications. Drugs Aging. 2008;25(4):307-324.

45. Modig S, Kristensson J, Troein M, Brorsson A, Midlov P. Frail elderly patients' experiences of information on medication. A qualitative study. BMC Geriatr. 2012;12(1):46.

46. Gransjön Craftman A, Hammar LM, von Strauss E, Hillerås P, Westerbotn M. Unlicensed personnel administering medications to older persons living at home: a challenge for social and care services. Int J Older People Nurs. 2015;10(3):201-210.

47. Hinton L, Apesoa-Varano EC, Unutzer J, Dwight-Johnson M, Park M, Barker JC. A descriptive qualitative study of the roles of family members in older men's depression treatment from the perspectives of older men and primary care providers. Int J Geriatr Psychiatry. 2015; 30(5):514-522.

48. Lee JI, Cutugno C, Pickering SP, et al. The patient care circle: a descriptive framework for understanding care transitions. J Hosp Med. 2013;8(11):619-626.

49. Murray MD, Morrow DG, Weiner M, et al. A conceptual framework to study medication adherence in older adults. Am J Geriatr Pharmacother. 2004;2(1):36-43.

50. Legrain S. Haute Autorité de Santé; 2005. Consommation Médicamenteuse chez le Sujet Agé. Consommation, Prescription, Iatrogénie et Observance [Medication use among older adults: use, prescription, iatrogenics and adherence]. Available from: https://www.has-sante.fr/portail/upload/ docs/application/pdf/pmsa_synth_biblio_2006_08_28_16_44_51_580. pdf. Accessed January 15, 2018. French.

51. Allenet B, Guignon AM, Maire P, Calop J. Intégration des représentations de la personne âgée face à ses médicaments pour améliorer son observance [Integration of the elderly person's representations regarding his medication to improve his compliance]. J Pharm Clin. 2005;24(3):175-179. French.

52. Flick U. Mantras and myths: the disenchantment of mixed-methods research and revisiting triangulation as a perspective. Qual Inq. 2017; 23(1):46-57.

53. Actualités, Office fédéral de la statistique (OFS); 2016. Statistique médicale des hôpitaux 2015 [Medical statistics from hospitals 2015]. Available from: https://www.bfs.admin.ch/bfs/fr/home/statistiques/ sante/systeme-sante/hopitaux/patients-hospitalisations.html. 2017. Accessed January 15, 2018. French.

54. Direct CCPLS, (CCSPA) DPAAAD; Canton de Vaud; 2011. Commission consultative pour le soutien direct des proches aidants actifs à domicile: Rapport d'activité 2011-2012 [Advisory committee for the direct support of active family caregivers at home: activity report 2011-2012]. Available from: https://www.vd.ch/themes/ soutien-social-et-aides-financieres/proches-aidants/commissionconsultative-du-soutien-aux-proches-aidants/. Accessed January 15, 2018. French. 
55. Dew K, Chamberlain K, Hodgetts D, Norris P, Radley A, Gabe J. Home as a hybrid centre of medication practice. Sociol Health Illn. 2014; 36(1):28-43.

56. Carpiano RM. Comme and take a walk with me: the "go-along" interview as a novel method for studying the implications of place for health and well-being. Health Place. 2009;15(1):263-272.

57. Fainzang S. Les médicaments dans l'espace privé: gestion individuelle ou collective [Medicines in private space: individual or collective management]. Anthropologie et Sociétés. 2003;27(2):139-154. French.

58. Haxaire C. "Calmer les nerfs": automédication, observance et dépendance à l'égard des médicaments psychotropes [Calming the nerves: self-medication, compliance and dependence on psychotropic drugs]. Sciences Sociales Et Santé. 2002;20(1):63-88. French.

59. Polak L, Green J. Using joint interviews to add analytic value. Qual Health Res. 2016;26(12):1638-1648.
60. Salter C. Compliance and concordance during domiciliary medication review involving pharmacists and older people. Sociol Health Illn. 2010;32(1):21-36.

61. Elo S, Kyngäs H. The qualitative content analysis process. J Adv Nurs. 2008;62(1):107-115.

62. Ratinaud P, Déjean S. Implémentation de la méthode ALCESTE d'analyse de texte dans un logiciel libre. Modélisation Appliquée aux Sciences Humaines et Sociales MASHS [Implementation of the ALCESTE method to text in a free software analysis. Modeling applied to the humanities and social MASHS]. Available from: http://docplayer.fr/10422759Iramuteq-implementation-de-la-methode-alceste-d-analyse-de-textedans-un-logiciel-libre.html. Accessed January 15, 2018. French.

63. Baker PG; World Health Organization (WHO); 2010. Framework for action on interprofessional education and collaborative practice. Available from: http://www.who.int/hrh/resources/framework_action/en/. Accessed January 15, 2018.

\section{Publish your work in this journal}

Patient Preference and Adherence is an international, peer-reviewed, open access journal that focuses on the growing importance of patient preference and adherence throughout the therapeutic continuum. Patient satisfaction, acceptability, quality of life, compliance, persistence and their role in developing new therapeutic modalities and compounds to optimize clinical outcomes for existing disease states are major areas of interest for the journal. This journal has been accepted for indexing on PubMed Central. The manuscript management system is completely online and includes a very quick and fair peer-review system, which is all easy to use. Visit http://www. dovepress.com/testimonials.php to read real quotes from published authors.

Submit your manuscript here: http://www.dovepress.com/patient-preference-and-adherence-journal 